\title{
Borrelia burgdorferi sensu lato prevalence in tick populations in Estonia
}

\author{
Julia Geller ${ }^{1,2^{*}}$, Lidia Nazarova ${ }^{1,2}$, Olga Katargina ${ }^{1}$ and Irina Golovljova ${ }^{1}$
}

\begin{abstract}
Background: Estonia is located in a unique area of co-distribution of Ixodes ricinus and I. persulcatus, which are the main tick vectors of Borrelia burgdorferi sensu lato. In the last decade, the incidence rate of Lyme borreliosis in Estonia has increased dramatically up to 115.4 per 100,000 in 2012. Here we present the first survey of the presence, the prevalence and genetic characteristics of B. burgdorferi s.l. complex spirochetes in the tick population in Estonia.

Methods: During the years 2006-2009, 2833 unfed Ixodes ricinus and I. persulcatus were collected from 43 sites in 7 counties in mainland Estonia as well as in 10 sites on the Saaremaa Island. DNA samples from ticks were analyzed individually using nested PCR of the ribosomal 5S-23S spacer region followed by bidirectional sequencing.

Results: The overall estimated prevalence of B. burgdorferi s.I was $9.7 \%$ and varied from $4.9 \%$ to $24.2 \%$ on the mainland and to $10.7 \%$ in Saaremaa Island. Ixodes persulcatus ticks showed significantly higher prevalence rates compared to that in I. ricinus-16.3\% and $8.2 \%$, respectively. The most prevalent genospecies was B. afzelii which was detected in $53.5 \%$ of Borrelia-positive ticks, followed by B. garinii and B. valaisiana with $26.2 \%$ and $5.5 \%$, respectively. Also, B. bavariensis and B. burgdorferi s.s. DNA in single I. ricinus ticks were detected. Borrelia afzelii, B. garinii and B. valaisiana were detected in both tick species. Two genetic subgroups of B. garinii (NT29 and 20047) and two genetic subgroups of B. afzelii (NT28 and VS461) were found to be circulating in all studied regions as well as in both tick species, except B. garinii subgroup NT29, which was found only in I. persulcatus ticks.

Conclusions: In the current study we detected the circulation of five B. burgdorferi s.l. genospecies and estimated the prevalence in ticks in different regions of Estonia. Detection and genetic characterization of Borrelia genospecies, especially those of public health importance, in the natural foci may help assessing high risk areas of human exposure to B. burgdorferi s.l.
\end{abstract}

Keywords: Ticks, Borrelia burgdorferi sensu lato, Ixodes, Lyme disease

\section{Background}

Ticks are important vectors of human and animal pathogens of viral, bacterial and protozoan nature worldwide. Lyme borreliosis (LB) is the most widely spread and most frequent tick-borne bacterial disease in Europe with an estimated 65,500 human cases annually [1]. In Estonia the incidence rate of LB has increased in the last decade from 23.4 in 2002 to 115.4 per 100,000 in 2012 [2], which are the highest rates in the Baltic region [3].

The causative agents of LB are the members of Borrelia burgdorferi sensu lato complex spirochetes of which

\footnotetext{
* Correspondence: julia.geller@tai.ee

*Correspondence: julia.geller@tai.ee
'Department of Virology, National Institute for Health Development, Hiiu 42, 11619, Tallinn, Estonia

${ }^{2}$ Department of Gene Technology, Tallinn University of Technology, Faculty Department of Gene Tech
of Science, Tallinn, Estonia
}

\section{Biomed Central}

(c) 2013 Geller et al.; licensee BioMed Central Ltd. This is an Open Access article distributed under the terms of the Creative Commons Attribution License (http://creativecommons.org/licenses/by/2.0), which permits unrestricted use, distribution, and reproduction in any medium, provided the original work is properly cited.
B. afzelii, B. garinii, B. spielmanii and B. burgdorferi sensu stricto are known to be pathogenic for humans, and B. valaisiana, and B. lusitaniae are considered potentially pathogenic [4]. The first five of these genospecies are widely spread in Europe with a predominance of $B$. afzelii and $B$. garinii [5]. It has been shown that rodents are the main reservoir for B. afzelii [6] and B. bavariensis [7], while $B$. garinii and $B$. valaisiana are associated mostly with birds $[8,9]$ and $B$. burgdorferi s.s. circulates in both rodent and avian hosts [10].

Ticks of the Ixodes spp. are the main vectors for Borrelia spirochetes. Ixodes ricinus and I. persulcatus ticks are the main vectors of $B$. burgdorferi s.l. in the natural foci in Europe and Asia. Nymphs are the most important in the infection cycle, while the role of adults 
is insignificant, as male Ixodes ticks usually do not feed and female ticks prefer feeding on larger mammals that are usually not competent hosts for Borrelia spirochetes [11]. Borrelia burgdorferi s.l. is transmitted transstadially, while transovarial transmission of spirochetes from the female to her offspring is a rare event $[5,12]$. Larvae acquire Borrelia during their first bloodmeal on an infected competent reservoir hosts. After molting to nymphs they transmit the infection to new uninfected hosts while feeding. Effective transmission of Borrelia from infected to uninfected ticks via co-feeding has also been shown to occur without development of systemic infection in hosts $[13,14]$.

Estonia is situated in the area of $I$. ricinus and $I$. persulcatus co-distribution providing a special setting in Eastern Europe for the study of tick-borne pathogens.

A previous report from Vormsi Island has shown the presence of B. burgdorferi s.l. genospecies in I. ricinus ticks [15]. The present study is the first survey of detection and genetic characterization of $B$. burgdorferi s.l. genospecies in both tick species in different regions in mainland Estonia as well as on the Saaremaa Island.

\section{Methods}

\section{Tick collection}

Ticks were collected at 43 sites in 8 counties in mainland Estonia and 10 sites on the largest island Saaremaa during the years 2006-2009. All study sites on the mainland were grouped into 7 regions according to their geographical and administrative location, whereas 4 regions with a total of 34 sites were located in the zone of I. ricinus and I. persulcatus sympatry (Figure 1).

Questing nymphs and adult ticks of both tick species were collected by passing a $1 \mathrm{~m}^{2}$ flannel flag over the vegetation during the tick activity period from April until October in 2006-2009. The cloths were examined after every $5 \mathrm{~m}$, all ticks were removed with forceps and maintained alive until later identification. Tick species, sex and stage were identified morphologically using a stereomicroscope. All ticks were investigated individually. Ticks were homogenized in 300 microliters of PBS with TissueLyzer (Haas, Germany). Two hundred microliters of suspension were used for DNA extraction and one hundred microliters were stored at $-70^{\circ} \mathrm{C}$.

\section{DNA extraction}

The guanidinium thiocyanate-phenol-chloroform method with TriPure isolation system (Roche Diagnostics, Lewes, UK) was used for DNA extraction according to the manufacturer's recommendations. Sterile water was included as a negative control for every DNA preparation set. DNA was kept at $-20^{\circ} \mathrm{C}$ until further use.

\section{PCR amplifications}

Screening of ticks was performed by PCR amplification of partial $16 \mathrm{~S}$ rRNA genes, and the 5S-23S intergenic spacer region was used for the detection of B. burgdorferi s.l. genospecies. The presence of Borrelia species was detected by amplification of $16 \mathrm{~S}$ rRNA gene as described [16] under the following conditions: 35 cycles, $94^{\circ} \mathrm{C}-10 \mathrm{sec}$, $60^{\circ} \mathrm{C}-1 \mathrm{~min}, 72^{\circ} \mathrm{C}-90 \mathrm{sec}$. Nested PCR was performed with primer pair 16S-Bor-S4F and 16S-Bor-S3R [17] and cycling conditions included 35 cycles of initial denaturation at $94^{\circ} \mathrm{C}$ for $10 \mathrm{sec}$, annealing at $65^{\circ} \mathrm{C}-1 \mathrm{~min}$, and elongation at $72^{\circ} \mathrm{C}-90 \mathrm{sec}$.

A B. burgdorferi s.l. group-specific 5S-23S intergenic spacer (IGS) region PCR was used for amplification and sequencing the $16 \mathrm{~S}$-positive samples as described earlier $[18,19]$, with some modifications. Cycling conditions for the first round PCR included an initial denaturation step for $1 \mathrm{~min}$ at $94^{\circ} \mathrm{C}$, followed by 35 cycles for $1 \mathrm{~min}$ at $94^{\circ} \mathrm{C}$, $1 \mathrm{~min}$ at $58^{\circ} \mathrm{C}$ and $2 \mathrm{~min}$ at $72^{\circ} \mathrm{C}$, and a final extension for $15 \mathrm{~min}$ at $72^{\circ} \mathrm{C}$. In the nested PCR, annealing temperature was decreased to $52^{\circ} \mathrm{C}$ and amplification was performed for 30 cycles.

The amplified products were visualized by electrophoresis in a $1 \%$ agarose gel, stained with ethidium bromide. Negative and positive control samples were included in each step of PCR amplification. Sterile deionised water was used as negative control. Samples of B.burgdorferi s.l. genospecies DNA obtained from culture (B. afzelii strain NE632, B. garinii strain NE11, B. burgdorferi s.s. strain B31, B. valaisiana strain VS116 and B. lusitaniae strain PotiB1; kindly provided by Lise Gern) as well as from ticks, were used as positive controls. To minimize contamination risks, all steps were performed in four separate rooms using sterile techniques. The sample DNA addition step to the PCR mix was performed under laminar flow.

\section{DNA sequencing and phylogenetic analysis}

Positive samples were sequenced with inner primers for 5S-23S IGS and 16S rRNA PCR, NC3 and NC4, and 16SBor-S4F and 16S-Bor-S3R, respectively. All PCR products were sent to the Estonian Biocenter (Tartu, Estonia) where sequencing was performed. Retrieved sequences were assembled, edited and analyzed with BioEdit v. 7.0.9.0 [20]. The UPGMA method was used for phylogenetic tree reconstruction using MEGA 5.0 package programs [21] with bootstrap analysis of 1000 replicates. The Maximum Likelihood Composite method was used for estimation of evolutionary distances in the units of base substitutions per site. Gamma distribution (shape parameter =1) was used for modeling the rate variation among sites. The analysis involved 79 nucleotide sequences of 260 total positions in the final dataset.

\section{Statistical analysis}

The $95 \%$ confidence interval (CI) of a proportion was estimated without a correction for continuity [22,23]. Statistical significance $(\mathrm{P})$ of the B. burgdorferi s.l. prevalence 


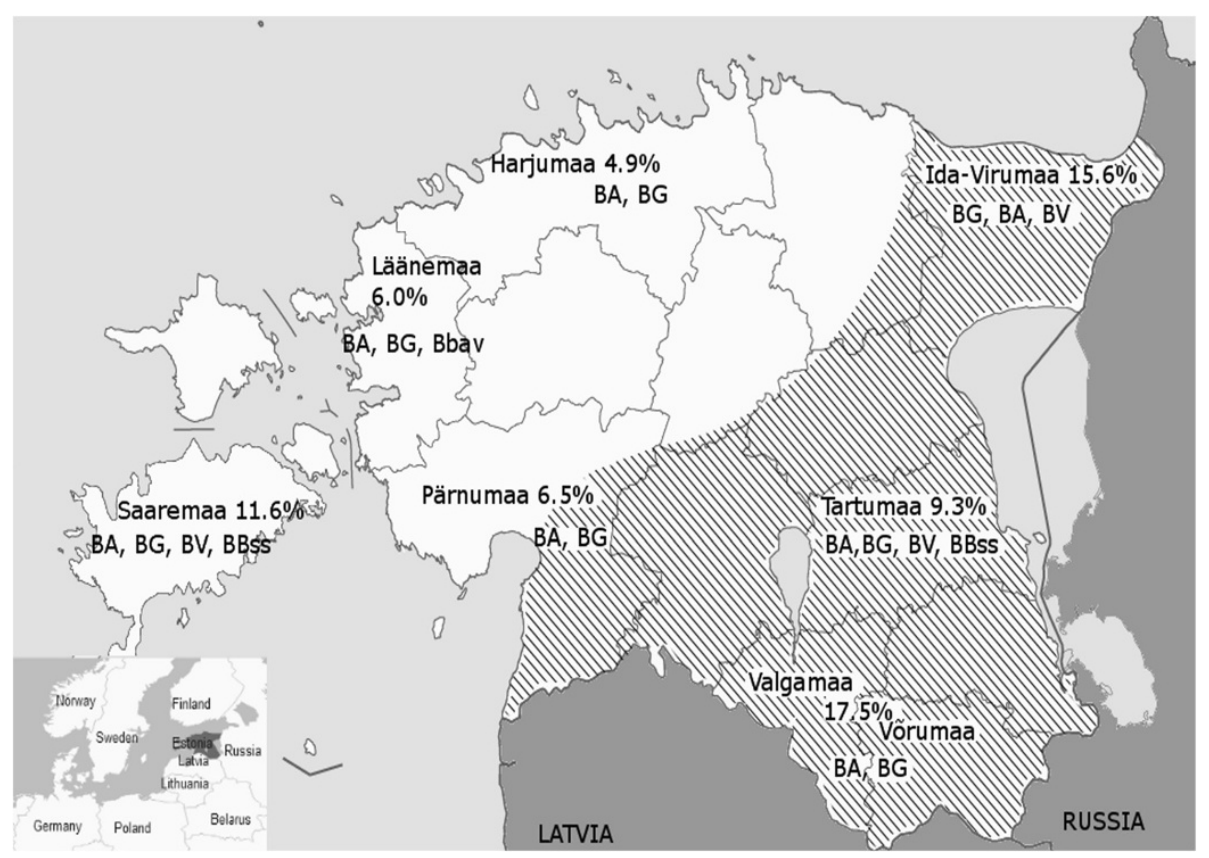

Figure 1 Tick sampling sites and B. burgdorferi s.l. genospecies in Estonia. Sites are grouped into regions according to their geographical and administrative locations. Regions are named according to their administrative location. The sympatric area for I. persulcatus and I. ricinus tick species is dashed according to Golovljova, I. unpublished data. BA- B. afzelii, BG- B. garinii, BV- B. valaisiana, Bbss- B. burgdorferi s.S., Bbav - B. bavariensis. The prevalence values of the given region are calculated according to the total tick population of the region analyzed for the presence of $B$. burgdorferi s.l.

among independent values such as tick species, stages and sites was calculated using Fisher's exact test $2 \times 2$ contingency table [24] and Poisson probability test.

\section{Results}

\section{Detection of B. burgdorferi DNA}

A total of 2833 unfed ticks, belonging to species I. ricinus (80.9\%; 2293/ 2833) or I. persulcatus (19.1\%; 540/ 2833), were collected from the vegetation. I. ricinus ticks were collected in all regions of Estonia, while I. persulcatus ticks were found only in Eastern and Southern Estonia (Figure 1).

B. burgdorferi s.l. DNA was found in 275 out of 2833 ticks $(9.7 \%)$ collected in all 7 regions of study. The highest overall prevalence of B. burgdorferi s.l. (15.6\%- 17.7\%) was detected in the South-Eastern region of Estonia (Vorrumaa/Valgamaa, Ida-Virumaa), areas sympatric for $I$. ricinus and $I$. persulcatus, as well as in the allopatric area of the Saaremaa island (10.7\%) where only I. ricinus is found (Table 1).

The prevalence of $B$. burgdorferi s.l. in $I$. persulcatus ticks $(16.3 \%)$ was significantly higher than that in $I$. ricinus (8.2\%) (Table 1). The estimated infection rates within the sympatric area were twice as high in $I$. persulcatus ticks as in $I$. ricinus: $16.3 \%$ and $7.4 \%$, respectively. However, the prevalence of $B$. burgdorferi s.l. in I. ricinus ticks from the sympatric areas $(7.4 \%)$ did not differ much from that in allopatric areas (8.6\%) (Table 1).
In mainland Estonia, the total prevalence rate of B. burgdorferi s.l. in both tick species in the sympatric area was significantly higher when compared to the prevalence rates in $I$. ricinus ticks in the allopatric area, $10.8 \%$ and $5.3 \%$, respectively $(\mathrm{P}<0.0001)$, while on Saaremaa Island the infection rate of $I$. ricinus was almost twice as high as in its mainland allopatric area (10.7\% and 5.3\%, respectively).

Adult ticks displayed higher infection prevalence than nymphs for both $I$. ricinus $(9.4 \%$ for adults and $6.6 \%$ for nymphs) and I. persulcatus species (18.5\% for adults and $8.0 \%$ for nymphs) (Table 1 ).

\section{Detection of B.burgdorferi s.l. genospecies}

All ticks were investigated individually for the presence of B. burgdorferi s.l. by PCR amplification of partial $16 \mathrm{~S}$ rRNA and 5S-23S IGS region genes. A total of 238 tick samples out of 275 positive for B. burgdorferi s.l. were genotyped by sequencing of PCR products and 37 samples $(13.5 \%)$ contained a mix of different B. burgdorferi genospecies that could not be individually identified.

B. afzelii was the most prevalent genospecies in all study regions comprising $53.5 \%$ of all B. burgdorferi s.l. infected ticks, and was detected in both I. ricinus (56.1\%) and I. persulcatus (47.7\%) ticks (Table 2). Analysis of nucleotide sequences showed that the investigated samples belong to two genomic subgroups of B. afzelii, VS461 and NT28 [25-27], that were detected in $62.6 \%$ and $28.6 \%$ of all 
Table 1 B. burgdorferi s.l. prevalence in questing ticks, collected in 7 regions in Estonia

\begin{tabular}{|c|c|c|c|c|c|c|c|c|c|c|c|c|c|c|}
\hline \multicolumn{7}{|c|}{ I. ricinus } & \multicolumn{6}{|c|}{ I. persulcatus } & \multirow{2}{*}{$\begin{array}{l}\text { Prevalence, } \\
\% \text { (total No. } \\
\text { ticks tested) }\end{array}$} & \multirow[t]{2}{*}{$95 \% \mathrm{Cl}$} \\
\hline \multicolumn{2}{|c|}{$\begin{array}{c}\% \text { prevalence } \\
\text { (No. nymphs tested) }\end{array}$} & $95 \% \mathrm{Cl}$ & $\begin{array}{l}\text { Prevalence, } \\
\% \text { (No. adults } \\
\text { tested) }\end{array}$ & 95\% Cl & $\begin{array}{l}\text { Prevalence, } \\
\% \text { (total No. } \\
\text { ticks tested) }\end{array}$ & $95 \% \mathrm{Cl}$ & $\begin{array}{l}\text { Prevalence,\% } \\
\text { (No. nymphs } \\
\text { tested) }\end{array}$ & $95 \% \mathrm{Cl}$ & $\begin{array}{l}\text { Prevalence,\% } \\
\text { (No. adults } \\
\text { tested) }\end{array}$ & $95 \% \mathrm{Cl}$ & $\begin{array}{l}\text { Prevalence, } \\
\% \text { (total No. } \\
\text { ticks tested) }\end{array}$ & $95 \% \mathrm{Cl}$ & & \\
\hline Ida-Virumaa & $9.5(21)$ & $2.6-28.9$ & $4.0(50)$ & $1.1-13.5$ & $5.6(71)$ & $2.2-13.6$ & $10.0(10)$ & $1.8-40.4$ & $23.2(99)$ & $16.0-32.5$ & 22.0 (109) & 15.3-30.1 & $15.6(180)$ & $11.0-21.6$ \\
\hline Tartumaa & $3.0(67)$ & $0.8-10.2$ & $10.9(230)$ & $7.5-15.6$ & $9.1(297)$ & $6.3-12.9$ & $7.8(102)$ & $4.0-14.7$ & 10.4 (192) & $6.9-15.6$ & $9.5(294)$ & $6.7-13.4$ & $9.3(591)$ & 7.2-11.9 \\
\hline Võrumaa-Valgamaa & - & & 9.9 (121) & $5.8-16.5$ & 9.9 (121) & $5.8-16.5$ & - & & $24.6(130)$ & $18.0-32.7$ & $24.6(130)$ & $18.0-32.7$ & $17.5(251)$ & $13.3-22.7$ \\
\hline Pärnumaa & 3.5 (198) & $1.7-7.1$ & $7.8(193)$ & $4.8-12.4$ & $5.6(391)$ & $3.8-8.4$ & $0 / 1^{a}$ & & $4 / 6^{a}$ & & $4 / 7^{\mathrm{a}}$ & & $6.5(398)$ & $4.5-9.4$ \\
\hline $\begin{array}{c}\text { Total in } \\
\text { sympatric area }\end{array}$ & $3.8(286)$ & $2.2-6.8$ & $9.1(594)$ & $7.0-11.7$ & $7.4(880) ¥$ & $5.8-9.3$ & $7.9(113)$ & $4.2-14.4$ & $18.5(79 / 427)$ & $15.1-22.5$ & $88 / 540(16.3) ¥$ & $13.4-19.6$ & $10.8(1420)^{* *}$ & $9.3-12.5$ \\
\hline Harjumaa & 3.4 (178) & $1.6-7.2$ & $6.6(166)$ & $3.7-11.5$ & 4.9 (344) & $3.1-7.8$ & - & & - & & - & & 4.9 (344) & $3.1-7.8$ \\
\hline Läänemaa & $8.0(100)$ & $4.1-15.0$ & $4.0(100)$ & $1.6-9.8$ & $6.0(200)$ & $3.5-10.2$ & - & & - & & - & & $6.0(200)$ & $3.5-10.2$ \\
\hline $\begin{array}{l}\text { Total in allopatric } \\
\text { area, mainland }\end{array}$ & $5.0(278)$ & $3.0-8.3$ & $5.6(266)$ & $5.6-14.4$ & $5.3(544)$ f\# & $3.7-7.5$ & & & & & & & $5.3(544)^{* *}$ & $3.7-7.5$ \\
\hline Saaremaa & $9.4(425)$ & $7.0-12.6$ & $11.9(444)$ & $9.3-15.3$ & 10.7 (869) 㧊 & $8.8-12.9$ & - & & - & & - & & 10.7 (869) & $8.8-12.9$ \\
\hline $\begin{array}{l}\text { Total in allopatric } \\
\text { area }\end{array}$ & 7.7 (703) & $5.9-9.9$ & $9.6(710)$ & $7.6-12.0$ & $8.6(1413)$ & $7.3-10.2$ & & & & & & & $8.6(1413)$ & 7.3-10.2 \\
\hline Total & 6.6 (989) ¥¥ & $5.2-8.3$ & 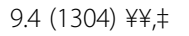 & 7.9-11.1 & $8.2(2293) *$ & $7.1-9.4$ & $8.0(113)+\dagger$ & $4.2-14.4$ & 18.5 (427) †十,‡ & $15.1-22.5$ & $16.3(540) *$ & 13.4-19.6 & 9.7 (2833) & $8.7-10.9$ \\
\hline
\end{tabular}

$¥, *, \neq, * *$, $\neq \neq$ Fisher's exact and Poisson probability tests $\mathrm{P}<0.0001$.

Cl-Confidence Interval of a Proportion.

a - no. of infected/ tested;\% prevalence as well as $95 \% \mathrm{Cl}$ were omitted due to small number of samples. 
Table 2 B. burgdorferi s.I. genotypes in I. ricinus and I. persulcatus tick species

\begin{tabular}{lccc}
\hline & $\begin{array}{c}\text { I. ricinus } \\
\text { No. of ticks positive/total } \\
\text { positive (prevalence, \%) }\end{array}$ & $\begin{array}{c}\text { I. persulcatus } \\
\text { No. of ticks positive/total } \\
\text { positive (prevalence, \%) }\end{array}$ & $\begin{array}{c}\text { TOTAL } \\
\text { No. of ticks positive/total } \\
\text { positive (prevalence, \%) }\end{array}$ \\
\hline B. afzelii VS461 & $60 / 187(32.1 \%)$ & $32 / 88(36.4 \%)$ & $92 / 275(33.5 \%)$ \\
B. afzelii NT28 & $37 / 187(18.8 \%)$ & $5 / 88(5.7 \%)$ & $42 / 275(15.3 \%)$ \\
VS461+ NT28 & $8 / 187(4.3 \%)$ & $5 / 88(5.7 \%)$ & $13 / 275(4.7 \%)$ \\
Total B. afzelii & $105 / 187(56.1 \%)$ & $42 / 88(47.7 \%)$ & $147 / 275(53.5 \%)$ \\
B. garinii 20047 & $38 / 187(20.3 \%)$ & $9 / 88(10.2 \%)$ & $47 / 275(17.1 \%)$ \\
B. garinii NT29 & $0 / 187$ & $25 / 88(28.4 \%)$ & $25 / 275(9.1 \%)$ \\
Total B. garinii & $38 / 187(20.3 \%)$ & $34 / 88(38.6 \%)$ & $72 / 275(26.2 \%)$ \\
B. valaisiana & $13 / 187(6.9 \%)$ & $2 / 88(2.3 \%)$ & $15 / 275(5.5 \%)$ \\
B. burgdorferi s.S. & $3 / 187(1.6 \%)$ & $0 / 88$ & $3 / 275(1.1 \%)$ \\
B. bavariensis & $1 / 187(0.5 \%)$ & $0 / 88$ & $1 / 275(0.4 \%)$ \\
Mix of several genotypes & $27 / 187(14.4 \%)$ & $10 / 88(11.4 \%)$ & $37 / 275(13.5 \%)$ \\
\hline
\end{tabular}

B. afzelii positive ticks, respectively. The nucleotide sequences of $5 \mathrm{~S}-23 \mathrm{~S}$ IGS share a high rate of similarity (99.1\%-100\% for VS461 and $98.3 \%-100 \%$ for NT28) with other $B$. afzelii sequences, reported from Russia, Belarus, Sweden, Switzerland, Italy, Turkey, Korea, China, Taiwan and Japan (Figure 2). The phylogenetic analysis of 5S-23S IGS rRNA gene revealed three lineages within $B$. afzelii subgroup VS461 and five in subgroup NT28, albeit with a bootstrap support of less than $70 \%$. The nucleotide sequence similarity between VS461 and NT28 subgroups ranged from $96.7 \%$ to $97.9 \%$. In addition, $8.8 \%$ of tick samples contained a mix of B. afzelii VS461 and NT28 (Table 3).

B. garinii was found in both tick species in all study regions. It was detected in $20.3 \%$ of $I$. ricinus and in $38.6 \%$ of $I$. persulcatus ticks, giving a total infection frequency of $26.2 \%$ of all B. burgdorferi s.l. infected ticks (Table 2). Estonian sequences found in the present study belong to 20047 (Eurasian) and NT29 (Asian) genomic subgroups. B. garinii group 20047 was the most prevalent $(65.3 \%)$ and was detected in both $I$. ricinus and I. persulcatus at $52.8 \%$ and $12.5 \%$ of B. garinii positive ticks, respectively (Table 3 ). B. garinii subgroup NT29 DNA was found only in $I$. persulcatus at $34.7 \%$ of $B$. garinii positive ticks. Estonian sequences of the 5S-23S IGS of the subgroup 20047 shared similarity rates of $96.8 \%-100 \%$, with sequences derived from GenBank and detected in Ixodes ticks and also in rodents in Russia, Czech Republic, Turkey, Ukraine, Belarus, Italy, UK, Italy, France, Switzerland and China. Within subgroup NT29, the Estonian sequences were identical with those amplified from ticks, rodents and human samples from Russia, Latvia and China with similarity rates from $98.9 \%$ to $100 \%$. Phylogenetic analysis based on 5S-23S IGS showed that Estonian samples reported in the current study are distributed within seven lineages in subgroup 20047 and five lineages in subgroup NT29 albeit with low bootstrap values (Figure 2).

B. valaisiana DNA was detected in $I$. ricinus ticks collected on Saaremaa Island and in both I. ricinus and I. persulcatus ticks collected in Tartumaa and Ida-Virumaa in the sympatric mainland area with an overall infection rate of 5.5\% (Table 2). The phylogenetic analysis based on 5S-23S IGS showed that Estonian sequences belong to B. valaisiana group VS116 and cluster with B. valaisiana sequences reported from Netherlands, Czech Republic and UK with similarity rates from $98.8 \%$ to $100 \%$ (Figure 2).

B. burgdorferi s.s. was found in three I. ricinus ticks (1.1\%) collected from Tartumaa and Saaremaa Island. Analysis of B. burgdorferi s.s. samples showed that all three Estonian sequences are identical to each other and cluster with sequences from Ixodes ticks and rodents from USA and Europe as well as with sequences from patients from the Czech Republic.

B. bavariensis DNA was detected in one I. ricinus tick $(0.4 \%)$ collected in Läänemaa. The nucleotide sequence of 5S-23S IGS of the Estonian sample was identical to the sequence of $B$. garinii strain PBi from Germany, which is a prototype strain for B. bavariensis.

\section{Discussion}

Estonia is situated in the unique area where the ranges of $I$. ricinus and $I$. persulcatus overlap in the Eastern and Southern parts. This fact may play an important role in the distribution and diversity of tick-borne pathogens. The study describes the first survey regarding the presence, the prevalence and genetic characteristics of B. burgdorferi s.l. genospecies in questing ticks collected from different sites in I. ricinus allopatric areas as well as in the areas sympatric for both tick species in Estonia. 


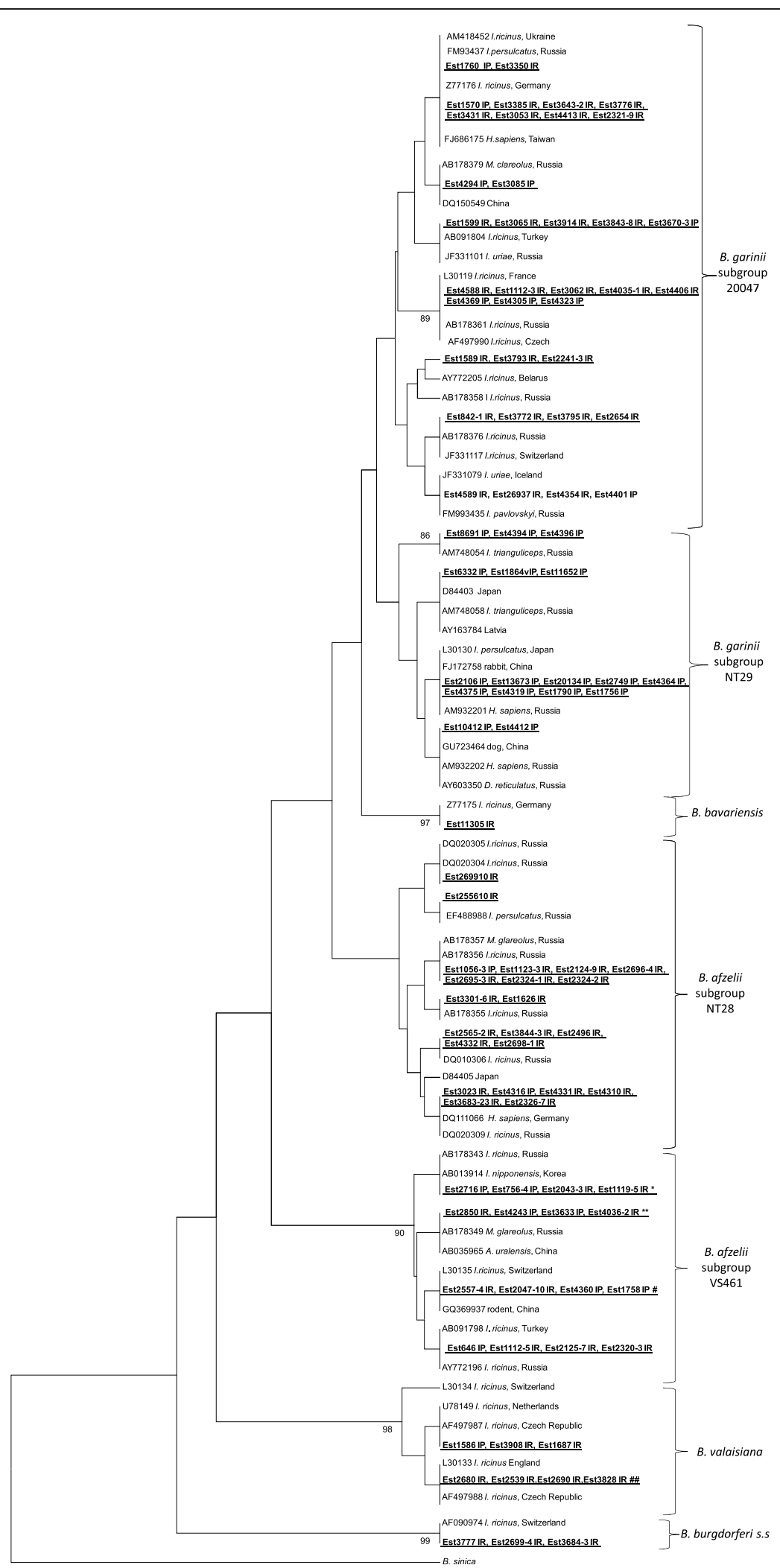

Figure 2 (See legend on next page.) 
(See figure on previous page.)

Figure 2 Phylogenetic tree (UPGMA) based on the partial sequences of $\boldsymbol{B}$. burgdorferi. s.l. 5S-23S rRNA IGS (235-253 bp). A sequence of $B$. sinica retrieved from GenBank was included as the outrgroup. Only support values exceeding $70 \%$ are shown. Sequences detected in the present study are shown in bold and underlined, and followed by label of tick species from which B. burgdorferi s.I. was amplified (IR- I. ricinus, IP- I. persulcatus). *identical to Est2043-2 IR, Est2559-3 IR, Est4268 IR, Est4583 IR, Est4396 IP, Est4397 IR, Est4400 IR, Est4374 IP, Est4372 IP, Est4373 IP, Est4361 IP, Est1116-2 IR, Est2557-7 IR, Est3915 IR, Est1642 IR, Est3703-4 IP, Est3670-1 IP, Est2325-2 IR, Est1625 IR. **identical to Est4255 IP, Est633-1 IP, Est1056-2 IP, Est1635 IR, Est4317 IP, Est4301 IP, Est2254-3 IR, Est3683-20 IR, Est1644 IR, Est1165-1 IP Est771 IP, Est1828 IP, Est4036-3 IR, Est2895-7 IR, Est3697-1 IP, Est3699-3 IP, Est2848 IR, Est2700-3 IR, Est2698-5 IR, Est2696-2 IR, Est2696-1 IR, Est2694-5 IR, Est1774 IP. \# identical to Est3918 IR, Est4586 IR, Est2112 IR, Est1639 IR, Est4359 IP, Est2320-7 IR, Est2319-3 IR, Est2253-1 IR, Est2244-10 IR, Est2692-2 IR, Est2304 IR, Est2031 IR, Est1758 IP. \#\#identical to Est3829 IR,Est3833 IR, Est3925 IR, Est 2242-9 IR, Est2696-8 IR, Est2699-9 IR, Est3840-4 IR.

The overall infection rate of ticks collected from vegetation $(\mathrm{n}=2283)$ was $9.7 \%$ as detected by PCR. Similar results have been reported from Sweden (11\%) [28], Lithuania (10.2\%) [29], Belarus (9.4\%) [30] and the Moscow region in Russia (13.3\%) [31]. In contrast, in neighboring Latvia, which also constitutes a sympatric area of I. ricinus and I. persulcatus, the B. burgdorferi s.l. prevalence in questing ticks was as high as $25.3 \%$ [32]. In neighboring Finland the prevalence of LB spirochetes in ticks is lower (5.1\%) [15], and similar to the infection rates detected in the current study on the mainland where only I. ricinus is distributed. However, the comparison of prevalence in the neighboring countries mentioned above is difficult due to the differences in sensitivity for the different methods used for Borrelia detection.

Both $I$. ricinus and $I$. persulcatus tick species are important vectors of B. burgdorferi s.l. in Eurasia. Moreover, it has been suggested that $I$. persulcatus ticks are more efficient vectors than $I$. ricinus for $B$. burgdorferi s.l. spirochetes in the natural foci [33]. This notion is in correspondence with the results of the current study and our previous investigations of B. miyamotoi [34] and tick-borne encephalitis virus (TBEV) [35], which showed significantly higher prevalences of these tick-borne pathogens (TBPs) in I. persulcatus than in $I$. ricinus. In addition, the reported infection rates of these TBPs from sympatric areas are higher than those from I. ricinus ranges. We suggest that in the Eastern Estonia where the I. ricinus and I. persulcatus ranges overlap, certain more favorable environmental, biotic or abiotic factors, may play a role in the enhanced of circulation of TBPs.

Table 3 B. afzelii and B. garinii genospecies in I. ricinus and $I$. persulcatus ticks

\begin{tabular}{lccl}
\hline & \multicolumn{1}{l}{ I. ricinus } & I.persulcatus & Total \\
\hline \multirow{4}{*}{ B. afzelii $($ No.147) } \\
VS461 & $60 / 147(40.8 \%)^{*}$ & $32 / 147(21.8 \%)^{*}$ & $92 / 147(62.6 \%)$ \\
NT28 & $37 / 147(25.2 \%)^{* *}$ & $5 / 147(3.4 \%)^{* *}$ & $42 / 147(28.6 \%)$ \\
VS461/NT28 mix & $8 / 147(5.4 \%)$ & $5 / 147(3.4 \%)$ & $13 / 147(8.8 \%)$ \\
B. garinii (No. 72) & \\
20047 & $38 / 72(52.8 \%) \dagger$ & $9 / 72(12.5 \%) \dagger$ & $47 / 72(65.3 \%)$ \\
NT29 & $0 / 72$ & $25 / 72(34.7 \%)$ & $25 / 72(34.7 \%)$ \\
\hline
\end{tabular}

$*{ }^{* *}, \dagger$ Fisher's exact test $\mathrm{P}<0.001$.
According to the model, based on temperature, climate and vegetation data, recently presented by Estrada-Peňa et al. [36], the Western coastline of Estonia has a different pattern of tick distribution compared to that of mainland Estonia. This may be one of the reasons why the prevalence of B. burgdorferi s.l. in ticks from Saaremaa Island, as well as previously reported data from Vormsi Island [15], differs from the infection rates in ticks from mainland Estonia. Similar findings have also been shown for B. miyamoto [34]. The high prevalence rates of B. burgdorferi s.l. in ticks from Saaremaa Island are in correspondence with data on the incidence rate of Lyme borreliosis, as the annual reported numbers of LB cases in Saaremaa are the highest in Estonia during the last decade. However, there might be other factors (abundance of small and large mammals, environment, microclimate etc.) that make the island a unique area with more favorable conditions for pathogen circulation.

Although adult ticks are not considered significant in the infection cycle of B. burgdorferi s.l., infection rates in adults are higher than in nymphs, because adult ticks have fed twice on different hosts [37]. In the current study the infection rates of adult ticks vs nymphs are higher for both $I$. ricinus and I. persulcatus, and are in correspondence with the values reported from regions with low infection rates in Europe in the meta analysis by Rauter and Hartung [37], as well as to those from the neighboring countries Finland [15], Latvia [38], Sweden [28].

\section{B.burgdorferi s.I. genospecies}

The presence of B. afzelii and B. garinii in Estonian ticks has been reported previously [15,39]. As in most European countries, the most prevalent B. burgdorferi s.l. genospecies in Estonian ticks were B. afzelii (53.5\%) and B. garinii (26.2\%) with prevalence rates in correspondence with data from neighboring regions Russia [40], Finland [41] and Latvia [38]. Several studies from Europe indicate a wide spread of B. afzelii and its subgroups NT28 and VS461 $[19,25]$ in different regions of Europe and Asia as well as in different vector species $[27,42]$. The fact that both genetic groups of B. afzelii and even a mix of these subgroups were found in I. ricinus as well as in I. persulcatus ticks in Estonia indicates a co-circulation of these genetic subgroups and their variants in the same natural foci and a 
sharing of vectors and hosts with no specific limitations. The genetic variants revealed in this study within both NT28 and VS461 subgroups also support the notion of a genetic heterogeneity of the $B$. afzelii genospecies circulating in Europe [27,43].

$B$. garinii is mostly associated with avian reservoirs, especially migratory passerines that can carry infected ticks over distances and even between continents [8]. Two genetic subgroups of $B$. garinii have been reported: subgroup 20047 ("European") that circulates in I. ricinus and I. persulcatus and has a wide geographical distribution over Eurasia, and subgroup NT29 ("Asian") [19], which has never been reported from I. ricinus up to date, and thus has a more limited geographic distribution. Thus, the detection of B. garinii subgroup NT29 in I. persulcatus ticks in Eastern Estonia makes this region, as well as areas of Eastern Latvia [32], a unique region in Eastern Europe of B. garinii subgroup NT29 circulation due to distribution of its main vector, I. persulcatus. The high nucleotide sequence identity of Estonian samples to the sequences reported from European and Asian countries and the detection of at least 11 genetic variants of $B$. garinii within both subgroups 20047 and NT29 are in agreement with the proposed wide geographical distribution of B. garinii as well as genetic heterogeneity of this Borrelia species [44,45].

$B$. valaisiana is also associated mostly with avian reservoirs [46,47], and our previous studies reported the detection of this Borrelia genospecies as well as B. garinii in ticks removed from migratory passerines [48]. In the current study we report the detection of $B$. valaisiana in questing ticks with infection rates similar to those reported from Sweden (6\%) [28] and Norway (6\%) [49]. To date there have only been rare reports on the detection of B. valaisiana in I. persulcatus ticks [50,51]. However, the detection of $B$. valaisiana in $I$. persulcatus ticks presented in the current study, as well as in Latvia [52] and in the Baltic regions of Russia [53], suggests that in areas sympatric for both I. ricinus and I. persulcatus, $B$. valaisiana may exchange tick vectors. Our studies on TBEV [35] and B. miyamotoi [34] also revealed that under conditions of I. ricinus and I. persulcatus sympatry, these TBPs may switch to a different tick vector and utilize both tick species as vectors. The events of sharing between tick species may also lead to adaptation of TBPs to a new vector, resulting in the spread of TBPs to new areas.

In European countries, B. burgdorferi s.s. is prevalent in I. ricinus ticks at different rates. In this study we report the presence of this Borrelia species in the Estonian I. ricinus population for the first time, albeit at a low rate $(0.1 \%)$. Although overall data presented previously in a meta analysis have shown about $16 \%$ of ticks to be infected with B. burgdorferi s.s. in Norway, Finland, Sweden and Estonia [37], data from the Baltic regions of Russia [53], Sweden [28], Latvia [38], Finland [15], and Belarus
[30] revealed infection rates ranging from 0.3 to $2.1 \%$, which correlates with the results of the current study.

In the present study we also report for the first time the presence of B. bavariensis in ticks in Estonia. This species seems to be limited to Central Europe [54] and has been reported from Switzerland [55], Austria, Germany and the Czech Republic [56]. While a high prevalence of B. bavariensis-like Borrelia in I. persulcatus ticks has been reported in Mongolia [57], this Borrelia genospecies was detected only in I. ricinus in our study.

A part of the ticks collected in the regions of this study and investigated for the presence of $B$. burgdorferi s.l., were also analyzed previously for $B$. miyamotoi, A. phagocytophilum and TBEV $[34,35,58]$. However, no co-infections with TBEV (628/2833) [35] or $A$. phagocytophilum (739/2833) [58] were found. Double infection with $B$. miyamotoi and $B$. burgdorferi s.l. was shown only for 4 ticks out of 2458, which were analyzed for both pathogens, as recently described by Geller et al. [34].

\section{Conclusions}

The recent study showed the circulation of five genospecies of $B$. burgdorferi s.l. complex, at least four of which, B. afzelii, B. garinii, B. bavariensis and B. burgdorferi s.s., are of medical importance. This study, as well as our previous investigations $[34,35]$, presented an exchange of TBPs between the natural tick vectors and sympatric tick species, that may indicate adaptation to a new vector species and lead to the expansion of TBPs to new geographical ranges. As the incidence rate of LB in Estonia is the highest in the Baltic regions and the annual number of LB cases remains high, the monitoring of Borrelia in its natural foci as well as in its natural hosts and tick vectors is of public health importance. This may also help the understanding of the ecology of TBPs and their vectors, as well as environmental, biotic and abiotic factors that may influence the abundance of ticks, prevalence of TBPs and the morbidity rates of tick-borne diseases.

\section{Abbreviations \\ LB: Lyme borreliosis; PCR: Polymerase chain reaction; rRNA: Ribosomal RNA; IGS: Internal transcribed spacer; Cl: Confidence interval; TBEV: Tick-borne encephalitis virus; TBP(s): Tick-borne pathogen(s).}

\section{Competing interests}

The authors declare that they have no competing interests.

\section{Authors' contributions}

JG, OK and IG carried out the field collections and morphological identifications. JG, LN, OK and IG carried out diagnostic protocols. JG, LN and IG carried out genetic studies, sequence alignments and drafted the manuscript. JG and IG participated in the design of the study and performed the statistical analysis. JG, LN, OK and IG conceived the study, and participated in its design and coordination and helped to draft the manuscript. All authors read and approved the final manuscript.

\section{Acknowledgments}

This work was supported by Estonian Science Foundation (http://www.hm.ee/) (Grant ETF 8691), Estonian Ministry of Education and Research (http://www.etf.ee/) 
(project SF0940033s09) and the European Regional Development Fund (Estonian Research Council (http://www.etag.ee/), programme TerVE, project ZoonRisk 3.2.1002.11-0002). The funders had no role in study design, data collection and analysis, decision to publish, or preparation of the manuscript.

Received: 5 April 2013 Accepted: 3 July 2013

Published: 9 July 2013

\section{Preferences}

1. Hubalek Z: Epidemiology of Lyme borreliosis. Curr Probl Dermatol 2009, 37:31-50.

2. Health Board: Estonian communicable disease bulletins. http://www.terviseamet. ee/en/cdc/estonian-communicable-disease-bulletins-2005-2012.html.

3. WHO: Centralized information system for infectious diseases. http://data.euro. who.int/cisid/.

4. Rudenko N, Golovchenko M, Grubhoffer L, Oliver JH Jr: Updates on Borrelia burgdorferi sensu lato complex with respect to public health. Ticks Tick Borne Dis 2011, 2:123-128.

5. Humair P, Gern L: The wild hidden face of Lyme borreliosis in Europe. Microbes Infect 2000, 2:915-922

6. Hanincova K, Schafer SM, Etti S, Sewell HS, Taragelova V, Ziak D, Labuda M, Kurtenbach K: Association of Borrelia afzelii with rodents in Europe. Parasitology 2003, 126:11-20.

7. Huegli D, Hu CM, Humair PF, Wilske B, Gern L: Apodemus species mice are reservoir hosts of Borrelia garinii OspA serotype 4 in Switzerland. J Clin Microbiol 2002, 40:4735-4737.

8. Comstedt P, Bergstrom S, Olsen B, Garpmo U, Marjavaara L, Mejlon H, Barbour AG, Bunikis J: Migratory passerine birds as reservoirs of Lyme borreliosis in Europe. Emerg Infect Dis 2006, 12:1087-1095.

9. Hanincova K, Taragelova V, Koci J, Schafer SM, Hails R, Ullmann AJ, Piesman J, Labuda M, Kurtenbach K: Association of Borrelia garinii and B. valaisiana with songbirds in Slovakia. Appl Environ Microbiol 2003, 69:2825-2830.

10. Baranton G, Postic D, Grimont PA, Assous M, Piffaretti JC, Boerlin P, Saint Girons I: Delineation of Borrelia burgdorferi sensu stricto, Borrelia garinii sp. nov., and group VS461 associated with Lyme borreliosis. Int I Syst Bacteriol 1992, 42:378-383.

11. Talleklint $L$, Jaenson TG: Transmission of Borrelia burgdorferi s.l. from mammal reservoirs to the primary vector of Lyme borreliosis, Ixodes ricinus (Acari: Ixodidae), in Sweden. J Med Entomol 1994, 31:880-886.

12. Richter D, Debski A, Hubalek Z, Matuschka FR: Absence of Lyme disease spirochetes in larval Ixodes ricinus ticks. Vector Borne Zoonotic Dis 2012, $12: 21-27$

13. Gern $L$, Rais O: Efficient transmission of Borrelia burgdorferi between cofeeding Ixodes ricinus ticks (Acari: Ixodidae). J Med Entomol 1996, 33:189-192.

14. Randolph SE, Gern L, Nuttall PA: Co-feeding ticks: Epidemiological significance for tick-borne pathogen transmission. Parasitol Today 1996, 12:472-479.

15. Makinen J, Vuorinen I, Oksi J, Peltomaa M, He Q, Marjamaki M, Viljanen MK: Prevalence of granulocytic Ehrlichia and Borrelia burgdorferi sensu lato in Ixodes ricinus ticks collected from Southwestern Finland and from Vormsi Island in Estonia. APMIS 2003, 111:355-362.

16. Fukunaga M, Takahashi Y, Tsuruta Y, Matsushita O, Ralph D, McClelland M, Nakao M: Genetic and phenotypic analysis of Borrelia miyamotoi sp. nov., isolated from the ixodid tick Ixodes persulcatus, the vector for Lyme disease in Japan. Int J Syst Bacteriol 1995, 45:804-810.

17. Fomenko NV, Livanova NN, Borgoiakov V, Kozlova IV, Shulaikina IV, Pukhovskaia NM, Tokarevich KN, Livanov SG, Doroshchenko EK, Ivanov LI: Detection of Borrelia miyamotoi in ticks Ixodes persulcatus from Russia. Parazitologiia 2010, 44:201-211.

18. Rar VA, Fomenko NV, Dobrotvorsky AK, Livanova NN, Rudakova SA, Fedorov EG, Astanin VB, Morozova OV: Tickborne pathogen detection, Western Siberia, Russia. Emerg Infect Dis 2005, 11:1708-1715.

19. Postic D, Assous MV, Grimont PA, Baranton G: Diversity of Borrelia burgdorferi sensu lato evidenced by restriction fragment length polymorphism of rif (5S)-rrl (23S) intergenic spacer amplicons. Int J Syst Bacterio/ 1994, 44:743-752.

20. Hall T: BioEdit: a user-friendly biological sequence alignment editor and analysis program for Windows 95/98/NT. Nucleic Acids Symp Ser 1999, 41:95-98.

21. Tamura K DJ, Nei M, Kumar S: MEGA4: Molecular Evolutionary Genetics Analysis (MEGA) software version 4.0. Mol Biol Evol 2007, 24:1596-1599.

22. Newcombe RG: Two-sided confidence intervals for the single proportion: comparison of seven methods. Stat Med 1998, 17:857-872.
23. Wilson EB: Probable Inference, the Law of Succession, and Statistical Inference. J Am Stat Assoc 1927, 22:209-212

24. Fisher RA: On the interpretation of $\times 2$ from contingency tables, and the calculation of P. J R Stat Soc 1922, 85:87-94.

25. Masuzawa T, Komikado T, Iwaki A, Suzuki H, Kaneda K, Yanagihara Y: Characterization of Borrelia sp. isolated from Ixodes tanuki, I. turdus, and I. columnae in Japan by restriction fragment length polymorphism of rrf (5S)-rrl (23S) intergenic spacer amplicons. FEMS Microbiol Lett 1996, 142:77-83.

26. Picken RN, Cheng Y, Strle F, Picken MM: Patient isolates of Borrelia burgdorferi sensu lato with genotypic and phenotypic similarities of strain 25015. J Infect Dis 1996, 174:1112-1115.

27. Fadeeva IA, Nefedova W, Korenberg El, Gorelova NB: Genetic variants of Borrelia afzelii, a pathogen of the ixodes tick borrelioses. Mol Gen Mikrobiol Virusol 2005, 3:18-22.

28. Fraenkel CJ, Garpmo U, Berglund J: Determination of novel Borrelia genospecies in Swedish Ixodes ricinus ticks. J Clin Microbiol 2002, 40:3308-3312.

29. Motiejunas L, Bunikis J, Barbour AG, Sadziene A: Lyme borreliosis in Lithuania. Scand J Infect Dis 1994, 26:149-155.

30. Reye AL, Stegniy V, Mishaeva NP, Velhin S, Hubschen JM, Ignatyev G, Muller CP: Prevalence of tick-borne pathogens in Ixodes ricinus and Dermacentor reticulatus ticks from different geographical locations in Belarus. PLoS One 2013, 8:e54476.

31. Masuzawa T, Kharitonenkov IG, Kadosaka T, Hashimoto N, Kudeken M, Takada N, Kaneda K, Imai Y: Characterization of Borrelia burgdorferi sensu lato isolated in Moscow province-a sympatric region for Ixodes ricinus and Ixodes persulcatus. Int J Med Microbiol 2005, 294:455-464.

32. Ranka R, Bormane A, Salmina K, Baumanis V: Identification of three clinically relevant Borrelia burgdorferi sensu lato genospecies by PCR-restriction fragment length polymorphism analysis of 16S-23S ribosomal DNA spacer amplicons. J Clin Microbiol 2004, 42:1444-1449.

33. Korenberg El, Kovalevskii YV, Levin ML, Shchyogoleva TV: The prevalence of Borrelia burgdorferi sensu lato in Ixodes persulcatus and I. ricinus ticks in the zone of their sympatry. Folia Parasitol (Praha) 2001, 48:63-68.

34. Geller J, Nazarova L, Katargina O, Jarvekulg L, Fomenko N, Golovljova I: Detection and genetic characterization of relapsing fever spirochete Borrelia miyamotoi in Estonian Ticks. PLoS One 2012, 7:e51914.

35. Katargina O, Russakova S, Geller J, Kondrusik M, Zajkowska J, Zygutiene M, Bormane A, Trofimova J, Golovljova I: Detection and characterization of tick-borne encephalitis virus in Baltic countries and eastern Poland. PLoS One 2013, 8:e61374.

36. Estrada-Pena A, Farkas R, Jaenson TG, Koenen F, Madder M, Pascucci I, Salman M, Tarres-Call J, Jongejan F: Association of environmental traits with the geographic ranges of ticks (Acari: Ixodidae) of medical and veterinary importance in the western Palearctic. A digital data set. Exp Appl Acarol 2013, 59:351-366.

37. Rauter C, Hartung T: Prevalence of Borrelia burgdorferi sensu lato genospecies in Ixodes ricinus ticks in Europe: a metaanalysis. Appl Environ Microbiol 2005, 71:7203-7216.

38. Etti S, Hails R, Schafer SM, De Michelis S, Sewell HS, Bormane A, Donaghy M, Kurtenbach K: Habitat-specific diversity of Borrelia burgdorferi sensu lato in Europe, exemplified by data from Latvia. App/ Environ Microbio/ 2003, 69:3008-3010.

39. Postic D, Korenberg E, Gorelova N, Kovalevski W, Bellenger E, Baranton G: Borrelia burgdorferi sensu lato in Russia and neighbouring countries: high incidence of mixed isolates. Res Microbiol 1997, 148:691-702.

40. Korotkov lu S, Kislenko GS, Burenkova LA, Rudnikova NA, Karan LS: Spatial and temporal variability of Ixodes ricinus and Ixodes persulcatus infection with the Lyme disease agent in Moscow Region. Parazitologiia 2008, 42:441-451

41. Junttila J, Peltomaa M, Soini H, Marjamaki M, Viljanen MK: Prevalence of Borrelia burgdorferi in Ixodes ricinus ticks in urban recreational areas of Helsinki. J Clin Microbiol 1999, 37:1361-1365.

42. Fadeeva IA, Korenberg El, Nefedova W, Andreichuk lu V, Markov AV, Shaginian IA: Genetic heterogeneity of Borrelia afzelii in the natural focus of the Middle Urals. Zh Mikrobiol Epidemiol Immunobiol 2006, 3:27-30.

43. Bunikis J, Garpmo U, Tsao J, Berglund J, Fish D, Barbour AG: Sequence typing reveals extensive strain diversity of the Lyme borreliosis agents Borrelia burgdorferi in North America and Borrelia afzelii in Europe. Microbiology 2004, 150:1741-1755.

44. Comstedt P, Asokliene L, Eliasson I, Olsen B, Wallensten A, Bunikis J, Bergstrom S: Complex population structure of Lyme borreliosis 
group spirochete Borrelia garinii in subarctic Eurasia. PLoS One 2009, 4:e5841.

45. Nefedova W, Korenberg El, Gorelova NB: Genetic variants of Borrelia garinii, a widely spread Eurasian pathogen of ixodid tick borreliosis. Mol Gen Mikrobiol Virusol 2010, 3:7-12.

46. Hubalek Z: An annotated checklist of pathogenic microorganisms associated with migratory birds. J Wild Dis 2004, 40:639-659.

47. Humair PF, Postic D, Wallich R, Gern L: An avian reservoir (Turdus merula) of the Lyme borreliosis spirochetes. Zentralbl Bakteriol 1998, 287:521-538.

48. Geller J, Nazarova L, Katargina O, Leivits A, Jarvekulg L, Golovljova I: Tick-borne pathogens in ticks feeding on migratory passerines in Western part of Estonia. Vector Borne Zoonotic Dis 2013, 13:443-448.

49. Jenkins $A$, Hvidsten $D$, Matussek A, Lindgren PE, Stuen S, Kristiansen BE: Borrelia burgdorferi sensu lato in Ixodes ricinus ticks from Norway: evaluation of a PCR test targeting the chromosomal flaB gene. Exp Appl Acarol 2012, 58:431-439.

50. Saito K, Ito T, Asashima N, Ohno M, Nagai R, Fujita H, Koizumi N, Takano A, Watanabe $\mathrm{H}$, Kawabata $\mathrm{H}$ : Case report: Borrelia valaisiana infection in a Japanese man associated with traveling to foreign countries. Am J Trop Med Hyg 2007, 77:1124-1127.

51. Lesnyak O, Laikovskaya E, Kufko I, Bruinink H, Baranova N, Rijpkema S: Clinical features of Lyme borreliosis in the middle Urals and distribution of Borrelia burgdorferi sensu lato species in local Ixodes persulcatus ticks. Zentralbl Bakteriol 1998, 288:111-119.

52. Bormane A, Lucenko I, Duks A, Mavtchoutko V, Ranka R, Salmina K, Baumanis V: Vectors of tick-borne diseases and epidemiological situation in Latvia in 1993-2002. Int J Med Microbiol 2004, 293(Suppl 37):36-47.

53. Alekseev AN, Dubinina HV, Van De Pol I, Schouls LM: Identification of Ehrlichia spp. and Borrelia burgdorferi in Ixodes ticks in the Baltic regions of Russia. J Clin Microbiol 2001, 39:2237-2242.

54. Franke J, Hildebrandt A, Dorn W: Exploring gaps in our knowledge on Lyme borreliosis spirochaetes - Updates on complex heterogeneity, ecology, and pathogenicity. Ticks Tick Borne Dis 2013, 4:11-25.

55. Gern L, Douet V, Lopez Z, Rais O, Moran Cadenas F: Diversity of Borrelia genospecies in /xodes ricinus ticks in a Lyme borreliosis endemic area in Switzerland identified by using new probes for reverse line blotting. Ticks Tick Borne Dis 2010, 1:23-29.

56. Skuballa J, Petney T, Pfaffle M, Oehme R, Hartelt K, Fingerle V, Kimmig P, Taraschewski H: Occurrence of different Borrelia burgdorferi sensu lato genospecies including B. afzelii, B. bavariensis, and B. spielmanii in hedgehogs (Erinaceus spp.) in Europe. Ticks Tick Borne Dis 2012, 3:8-13.

57. Scholz HC, Margos G, Derschum H, Speck S, Tserennorov D, Erdenebat N, Undraa B, Enkhtuja M, Battsetseg J, Otgonchimeg C, et al: High prevalence of genetically diverse Borrelia bavariensis-like strains in Ixodes persulcatus from Selenge Aimag, Mongolia. Ticks Tick Borne Dis 2013, 4:89-92.

58. Katargina O, Geller J, Alekseev A, Dubinina H, Efremova G, Mishaeva N, Vasilenko V, Kuznetsova T, Jarvekulg L, Vene S, et al: Identification of Anaplasma phagocytophilum in tick populations in Estonia, the European part of Russia and Belarus. Clin Microbiol Infect 2012, 18:40-46.

doi:10.1186/1756-3305-6-202

Cite this article as: Geller et al: Borrelia burgdorferi sensu lato prevalence

in tick populations in Estonia. Parasites \& Vectors 2013 6:202.

\section{Submit your next manuscript to BioMed Central and take full advantage of:}

- Convenient online submission

- Thorough peer review

- No space constraints or color figure charges

- Immediate publication on acceptance

- Inclusion in PubMed, CAS, Scopus and Google Scholar

- Research which is freely available for redistribution 